\title{
Professional Staff Turnover in Academic Libraries: A Case Study
}

\section{Dee Ann Allison and Eva Sartori}

This pilot study was undertaken at the University of Nebraska to identify factors contributing to the turnover of professional librarians. Librarians who left between 1974 and 1984 and librarians currently on staff were surveyed. The results indicate that relationships with supervisors, career goals, financial support, and pay are most important in deciding to leave. Factors that caused dissatisfaction among those who left are explored, and a model is presented for describing the decision-making process. Areas for additional research are suggested.

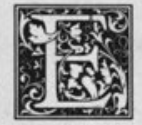

mployee turnover has been one of the most widely studied subjects in organizational psychology. Since the turn of the century, hundreds of studies have been conducted to determine the factors that cause individuals to leave an institution. This research has focused overwhelmingly on blue-collar and clerical populations in a manufacturing setting while neglecting professional employees and service institutions. The study of professional turnover in libraries has suffered from this neglect, although there are indications that librarians are becoming interested in the issue. ${ }^{1}$ In the past decade James Neal studied clerical turnover in libraries and Richard Rubin conducted a pilot study of librarians (not all of whom held the MLS) in three large Ohio public libraries. ${ }^{2}$ Only William Wong and David Zubatsky confined their study to professional librarians in their investigation of the length of service of university library directors. ${ }^{3}$ Because no research has been done so far on the turnover of professional academic librarians other than directors, and on the supposition that professionals have their own specific values and career expectations which differentiate them from paraprofessionals, the authors undertook a pilot study to examine turnover in this group at the University of Nebraska-Lincoln (UNL) between the years 1974 and 1984.

Because much of the budget in academic libraries is spent on salaries and fringe benefits, managers have to be concerned with the rate at which staff changes in their libraries. ${ }^{4}$ Undoubtedly some turnover is beneficial. Staff members are invigorated by new employees who arrive with fresh ideas and new perspectives and, in some instances, training in the latest technologies. Staff mobility also provides an outlet for dissatisfied personnel who might otherwise become disruptive or unproductive. Nevertheless, turnover is an expensive process. Recruitment involves substantial costs, including the cost of advertising, travel and lodging during the interview process, and the reduced productivity of employees involved in recruitment and training. The remaining employees experience stress as working relationships are disrupted and workload

Dee Ann Allison and Eva Sartori are Associate Professors at the University of Nebraska in Lincoln, Nebraska 68588-0410. 
is increased while new employees are recruited, hired, and trained. The process bears investigation.

\section{REVIEW OF THE LITERATURE}

After reviewing data from 120 research studies on turnover in a wide variety of organizations, John L. Cotton and Jeffrey M. Tuttle conducted a meta-analysis to summarize and assess findings on the subject of turnover. ${ }^{5}$ A meta-analysis consists of a series of statistical procedures that condense information; determine the direction of findings, i.e., whether the relationship is positive or negative; and assess their magnitude and statistical significance. In addition, Cotton and Tuttle used regression analysis to determine whether certain variables such as subject population or nationality moderated the relationship between turnover and correlates such as pay.

Cotton and Tuttle grouped the possible correlates of turnover into three categories: work related, personal, and external. Of the work-related factors, pay was strongly related to turnover, as were overall job satisfaction, satisfaction with the work itself and with supervision, and organizational commitment. The higher the pay or the greater the satisfaction with work and supervision or the greater the commitment to the organization, the less likely employees are to leave. Employees are more likely to remain in their current jobs if their performance is high and they are satisfied with colleagues and the opportunities for promotion.

Analyzing personal factors, Cotton and Tuttle confirmed the findings of earlier reviews which had concluded that age, tenure, met expectations, and number of dependents were negatively related to turnover. Thus, the turnover rate was lower among those who had been on the job longer, or who had more dependents, or among those employees who felt that their expectations were being met by their work. Research also indicated that the more educated the employee, the less likely s/he is to leave. Women were more likely to leave than men, and married employees somewhat less likely to leave than unmarried ones. Intelligence seemed to have little relation to turnover.

Two external factors, the presence of unions and employee perception of outside job alternatives, were found to be strongly related to turnover. The more employment alternatives were perceived to exist, the higher the turnover rate and vice versa. The presence of a union, on the other hand, seemed to act as a brake on turnover.

Regression analyses indicated that the type of employee population, the type of industry, and nationality moderated the relationship between correlates and turnover rates. Thus, pay was found to be more reliably related to turnover in the case of professionals than in the case of blue-collar and nonmanagerial workers. In service organizations, however, pay in general was less reliably related to turnover than in manufacturing. It is not surprising that satisfaction with the work was a more reliable correlate in service than in manufacturing organizations.

Research on turnover in libraries is still at a preliminary stage and has not yet yielded any significant results. The samples have been either small or lacking in homogeneity, and the conclusions are still very tentative. Wong and Zubatsky speculate that the increasingly longer tenure of library directors may be caused by more stringent economic conditions and by the restricted mobility of two-professional households. In the case of library directors, external and personal rather than job-related factors may affect the turnover rate. In the case of the nonprofessionals studied by Neal, there is also evidence that personal factors ("following graduating spouse" and "returning to school") are the most important causes of turnover. In the case of Rubin's respondents, which included both professionals and nonprofessionals, personal reasons also seem to be critical in deciding whether to stay at or leave an institution.

\section{METHODOLOGY}

As noted by Cotton and Tuttle, the type of employee population (white-collar or blue-collar) and the nature of the organization (service or manufacturing) moderate the relationship between correlates and 
turnover. Professionals and support staff may leave a service organization for quite different reasons. To identify some of the characteristics associated with the turnover of professional librarians, a study was undertaken at the University of NebraskaLincoln libraries. The authors sought to verify the connections between turnover and (1) biographical factors such as length of stay at the institution and intention to leave; (2) work-related factors such as competence of colleagues, autonomy on the job, opportunities for promotion, and satisfaction with pay; (3) personal factors such as family or health considerations; and (4) external factors such as the size of the town and the cultural and recreational opportunities of the region. External factors such as market conditions were outside the scope of our investigation.

An anonymous questionnaire was administered in 1984-1985 to currently employed professional librarians and to those librarians who had voluntarily left the libraries between 1974 and 1984. The questionnaire contained 77 items in all, grouped into five categories. The three work-related categories listed the characteristics of co-workers, job, and funding at UNL. Each of these categories was divided in two parts. Respondents were asked to check those factors in part A they considered very important in their decision to stay at or leave UNL and in part B, their degree of satisfaction with those factors they selected as very important.

\section{"Of the 28 professional librarians who left during the period studied, 20 had been at UNL less than 5 years."}

Space was also provided for respondents to describe their reasons for choosing to leave or for contemplating leaving the institution. The same format was used to explore the relationship between a fourth category, external factors, and turnover. In the fifth category the respondents were asked to provide some personal data about themselves.
Of the currently employed librarians, 30 (67\%) responded. Addresses were available for 51 of the 60 librarians who left between 1974 and 1984, and 28 (47\%) responded. Because the sample was small, in all our analyses significance was accorded only to those 28 items that $25 \%$ or more of the respondents considered very important (see table 1).

\section{RESULTS}

Two biographical characteristics, length of stay at the institution and intention to leave, proved to be significantly related to turnover. Of the 28 professional librarians who left during the period studied, 20 had been at UNL less than 5 years. It should be noted that less than $25 \%$ of those who left considered tenure very important in making a decision to leave or stay. Thus these librarians probably did not leave because they were afraid they would be denied tenure. Intention to leave was also strongly related to turnover in this study. Of the 24 previously employed librarians who responded to this question, 15 (63\%) indicated they were actively looking for other employment. Only 3 of the 24 were not actively thinking about leaving prior to applying for another job. Among those currently employed, only 5 were actively considering leaving UNL. Most of the librarians in this group seemed committed to staying at UNL at the time the study was conducted.

In analyzing the work-related causes of dissatisfaction of the librarians who left UNL, we found that money issues were dominant. Thirty-two percent were dissatisfied with their future salary prospects and $29 \%$ with the institution's support for travel, conferences, and research (see table 2, items 21 and 23). The relationship with the dean of libraries and the fulfillment of career goals were also important sources of dissatisfaction, as $29 \%$ were unhappy with each of these factors (see table 2 , items 6 and 28).

When the responses of both "leavers" and "stayers" are combined, an interesting pattern is revealed. Managers were more dissatisfied with the money categories than nonmanagers (see table 3 , items $20,21,22,23)$, while nonmanagers were 
TABLE 1

FACTORS CONSIDERED VERY IMPORTANT IN DECISION TO LEAVE OR STAY $(\mathrm{N}=58)^{*}$

\begin{tabular}{lcc}
\hline \hline & Leavers & Stayers \\
& $\mathrm{N}=28$ & $\mathrm{~N}=30$ \\
\hline 1. Intellectual stimulation among colleagues in the library & $29 \%$ & $13 \%$ \\
2. Competence of colleagues & 29 & 57 \\
3. The feeling of collegiality in the library & 25 & 33 \\
4. Your relationship with co-workers in your immediate section/unit & 36 & 53 \\
5. Your relationship with your immediate supervisor, if other than the dean, & 32 & 57 \\
associate or assistant dean & 29 & 20 \\
6. Your relationship with the dean of libraries & 11 & 33 \\
7. Your relationship with subordinates & 18 & 47 \\
8. Communication within your section/unit & 25 & 67 \\
9. Autonomy in executing duties & 21 & 47 \\
10. Opportunity for creativity & 36 & 70 \\
11. Stimulating work & 25 & 23 \\
12. Opportunity to change jobs within the library & 36 & 47 \\
13. Opportunity to participate in decision making & 14 & 27 \\
14. Performance expectations (work load) & 4 & 27 \\
15. Lack of age discrimination & 36 & 47 \\
16. Competence of your supervision & 25 & 23 \\
17. Level of encouragement for professional development & 18 & 33 \\
18. Lack of sexual discrimination & 7 & 53 \\
19. Adequacy of support staff & 32 & 47 \\
20. Salary & 43 & 53 \\
21. Future salary prospects & & \\
22. Institutional support for existing programs (e.g., collection development, & 25 & 50 \\
automation) & 29 & 43 \\
23. Institutional support for travel, conferences, and research & 25 & 23 \\
24. Size of the town & 36 & 40 \\
25. Cultural and recreational opportunities & 11 & 40 \\
26. Family considerations & 21 & 27 \\
27. Support for the library in the university community & 43 & 37 \\
28. Career goals & &
\end{tabular}

*This table includes only those factors with which at least $25 \%$ of either group were dissatisfied.

more dissatisfied with the institution's ability to fulfill their career goals (see table 3 , item 28).

Family considerations were considered very important by only $11 \%$ of the leavers and few of these expressed any dissatisfaction with this factor. The size of the town and its cultural and recreational opportunities were considered very important by $25 \%$ and $36 \%$ of the leavers respectively, but few were dissatisfied with the size while $25 \%$ were dissatisfied with the cultural and recreational opportunities.

How did the responses of those who left compare with those of the librarians who stayed? On the whole, the librarians who stayed were more dissatisfied than those who left. The leavers were more dissatisfied than the stayers only with the implementation of their career goals and their relationship with the dean (a new dean was appointed in 1985). It is worth noting that the librarians who left were less dissatisfied with money issues than the currently employed (see table 2, items 20, 21, $22,23)$. In the case of external factors, those who left were slightly more dissatisfied with the recreational and cultural opportunities than those who stayed (see table 2, item 25). Neither group was very dissatisfied with either the size of the town or their family situations.

At the end of the questionnaire, the former UNL librarians had the opportunity to state their reasons for leaving. If dissatisfaction led to turnover, we would expect the narrative responses to corroborate the results of the questionnaire. In other words, the librarians' departure would have been triggered by an aspect or aspects of their lives at work or in the immediate environment with which they 
TABLE 2

FACTORS WITH WHICH LIBRARIANS

EXPRESSED DISSATISFACTION $(\mathrm{N}=58)^{*}$

\begin{tabular}{lcc}
\hline \hline Question & Leavers & Stayers \\
\hline 6. Your relationship with the dean of libraries & $\mathrm{N}=28$ & $\mathbf{N}=30$ \\
19. Adequacy of support staff & 4 & $0 \%$ \\
20. Salary & 21 & 30 \\
21. Future salary prospects & 32 & 47 \\
22. Institutional support for existing programs (e.g., collection development, & 21 & 37 \\
automation) & 29 & 37 \\
23. Institutional support for travel, conferences, and research & 25 & 17 \\
25. Cultural and recreational opportunities & 29 & 20 \\
28. Career goals & & \\
\hline
\end{tabular}

-This table includes only those factors with which at least $25 \%$ of either group were dissatisfied.

TABLE 3

TOTAL DISSATISFIED*

\begin{tabular}{llc}
\hline \hline Question & $\begin{array}{c}\text { Managers } \\
\mathrm{N}=18\end{array}$ & $\begin{array}{c}\text { Nonmanagers } \\
\mathrm{N}=32\end{array}$ \\
\hline 13. Opportunity to participate in decision making & $11 \%$ & $25 \%$ \\
17. Level of encouragement for professional development & 33 & 6 \\
20. Salary & 39 & 19 \\
21. Future salary prospects & 50 & 38 \\
22. Institutional support for existing programs (e.g., collection devel- & 39 & 25 \\
opment, automation) & 50 & 25 \\
23. Institutional support for travel, conferences, and research & 17 & 25 \\
27. Support for the library in the university community & 17 & 34 \\
28. Career goals & & \\
\hline
\end{tabular}

*This table includes only those factors with which at least $25 \%$ of either group were dissatisfied.

were dissatisfied. In fact, the narrative responses underscored the important role dissatisfaction with managers, career goals, and money issues played in the individual's decision to leave. Fourteen of the 23 respondents to this part of the survey gave dissatisfaction with a supervisor as a reason for leaving, making this the most frequently mentioned cause of turnover for this group. The importance of career goals in the turnover decision was also emphasized by the narrative responses: 5 librarians left because of their interest in professional development, including exposure to automation, and four left for administrative advancement. Pay was the next most frequently given reason for leaving.

The narrative responses stressed the importance of work-related factors in the turnover decision. Of the 23 who described their reasons for leaving, only 4 failed to mention some aspect of the situation at work as a reason for leaving. In all,
43 of the 55 reasons given by 18 of the respondents included, beyond the major reasons listed above (supervisors, career goals, pay), such factors as dissatisfaction with colleagues, with the decision-making process, with communication between sections, and with their particular job description. Almost always, the respondents listed several conditions at work as reasons for leaving.

Few librarians who left felt that family considerations or closeness to relatives or friends were important in their decision to leave. However, 9 listed personal reasons as the cause of their departure. Of these, 3 listed personal reasons as the only reason for leaving. Two left because of a spouse's job, and the third left because of the need for personal growth. Geographical location was mentioned 6 times, but always in combination with other reasons.

\section{DISCUSSION}

The results suggest that employees who 
intend to leave will usually leave. The greatest mobility seems to occur among those with less than five years at the institution. Administrators can anticipate higher turnover rates among employees with less tenure on the job and among those who state an intention to leave.

Dissatisfaction with the job does not seem to be a potent reason for leaving because, as a group, the librarians who left were less dissatisfied than the current staff. However, strong dissatisfaction with one factor in the workplace, such as dissatisfaction with a supervisor or an administrator, may lead to a decision to leave.

Neither group expressed much interest (less than $25 \%$ ) in opportunities for administrative or faculty rank promotions or in the opportunity to conduct research. This lack of interest reveals some interesting attitudes on the part of the professional staff. Librarians at UNL have had faculty status since 1974, yet the rewards and obligations of academic status as defined by teaching faculty-the opportunity to conduct research or the higher status associated with a rise in rank-were not important to them and presumably had little effect on turnover at this institution. ${ }^{6}$ More important to the two groups studied were factors related to the actual performance of their job, the opportunity to do stimulating work (which did not seem to include research), relationships with their colleagues and their supervisor, and current and future salary prospects. The data at UNL suggest that the rewards of research and promotion are not significant enough in themselves to affect a librarian's decision to stay or leave.

Managers will not be surprised to discover that money issues, including support for travel, research, and library programs, were the greatest sources of dissatisfaction in both groups. However, they may be startled by the suggestion that these issues are a source of greater dissatisfaction to managers than to nonmanagers. Administrators concerned with turnover may need to worry more about raising the salaries of the employees who are better paid, i.e., the managers, than about improving the salaries of their nonmanagerial staff.

Few of the nonmanagers who left UNL took administrative positions. This may be attributable to their lack of managerial experience. But it is also possible that nonmanagers may be less interested in moving up than in pursuing additional specialization in their areas of interest. Staff development programs and autonomy in developing particular job descriptions may keep valued employees at the institution.

\section{"Staff development programs and autonomy in developing particular job descriptions may keep valued employees at the institution."}

The findings in this study indicate that the factors with which employees express dissatisfaction cause them to leave. However, the reason(s) most people leave do not necessarily explain why an individual chooses to leave. Thus, while few people in our study thought family reasons were important in making their decision to leave or stay and few were dissatisfied with their personal lives, for some the decision to leave was made solely on the basis of a spouse's employment possibilities.

While some aspect of a job may be more important than others, e.g., the relationship with a supervisor or the opportunity to implement career goals, employees may actually leave because of a factor or factors that are especially significant at a specific time. For example, while a feeling of collegiality may not be important to all employees, it may be vital to some. The causes of turnover and job attachment are so complex that general conclusions cannot be applied to the understanding of a specific case. It is incumbent on the manager to understand employees well enough to create the specific conditions that will keep valuable employees at the institution.

\section{MODEL}

The problem for the manager is to determine the effect that library conditions 


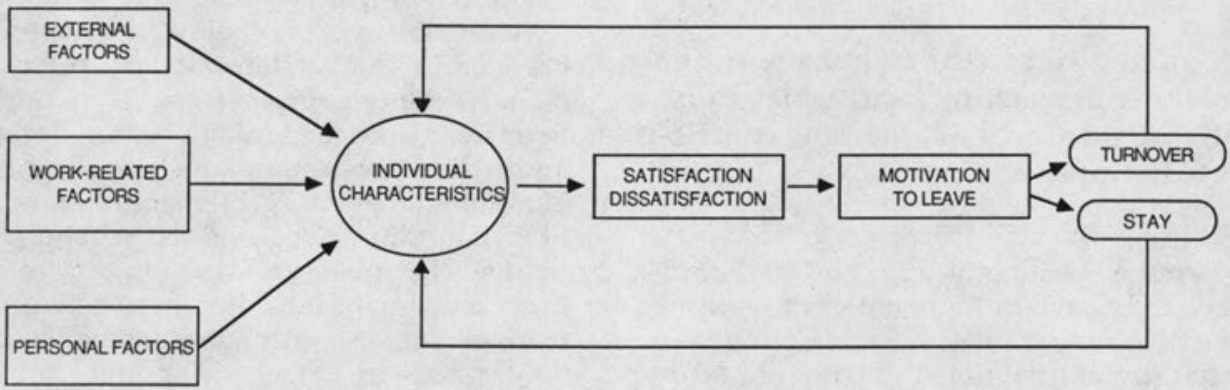

FIGURE 1

Turnover Model

have on turnover. The potential for turnover can be understood as a balance between factors that keep employees on the job and factors that drive them away. These factors are external, work related, and personal. Figure 1 shows the relationship between these categories and the decision to leave or stay at an institution.

The model emphasizes the importance of satisfaction or dissatisfaction in the decision-making process. The individual at the center of the process assigns positive, negative, or neutral values to situations. A negative value will cause dissatisfaction with the situation, a positive one satisfaction, and a neutral one indicates a lack of importance. The overall balance between satisfaction and dissatisfaction will determine the degree of motivation to leave.

Let us examine the three major categories that affect the decision to leave or stay. The "external environment" includes all the local conditions such as the attractiveness of the community, the quality of its schools, and its civic life, which are beyond the control of the employer. The second category, "work-related factors," encompasses the employee's relationships with co-workers and supervisors, funding, salary, working conditions, quality of management, the goals of the institution, and the characteristics of the individual job. The final category, "personal factors," reflects personal characteristics such as marital status and commitment to the institution.

The importance of these factors is deter- mined by the individual. For example, professional goals, the importance accorded to work as weighed against other responsibilities, the individual's particular position and status, and the attractiveness of the community necessarily affect the strength of attachment to the current job. These individual characteristics also color the perception of job potential at the institution. If employees believe the potential for growth and advancement is high, they are more likely to remain committed than if the potential is perceived to be low. The strength of this commitment determines the overall level of satisfaction with the current situation which in turn controls the degree of motivation to leave. Once the decision is made, the individual may reevaluate the situation and alter the importance of particular values.

\section{IMPLICATIONS FOR RESEARCH}

This study was conceived as a pilot in the investigation of turnover among professional librarians, and it posits that librarians are a distinct population with specific psychological characteristics, needs, and aspirations. According to this study, librarians consider their relations with their co-workers and the opportunity to do stimulating work to be very important to them. They are also concerned about funding, for themselves and their institutions, and less concerned about the local cultural and recreational climate. However, when tenure standards do not require it, they seem to care little about doing research, rising in rank, or interacting 


\section{"Forcing librarians to behave in the manner of teaching faculty may cause dissatisfaction and thereby contrib- ute to turnover."}

with the teaching faculty. Forcing librarians to behave in the manner of teaching faculty may cause dissatisfaction and thereby contribute to turnover. More work needs to be done on the impact of faculty status, privileges, and obligations on turnover rates among librarians.
Additional work also needs to be done to define the specific characteristics of librarians in comparison with nonprofessionals. Among professionals, distinctions need to be made along demographic and work-classification lines, e.g., managers/nonmanagers, catalogers/reference librarians, librarians/middle managers/ deans. Our observations suggest that there are significant differences between managers and nonmanagers and between employees with longer and shorter tenure at an institution. Because our sample was small, these observations need to be replicated by studies at other institutions.

\section{REFERENCES AND NOTES}

1. The Association of College and Research Libraries is supporting a study of turnover by James Neal, with the assistance of Gordon Fretwell.

2. James Neal, "Staff Turnover and the Academic Library," in Options for the 80's. Proceedings of the Second National Conference of the Association of College and Research Libraries, eds. Michael K. Kathman and Virgil F. Massman (Greenwich, Conn. and London: The JAI Pr. Inc., 1982), p.99-106; Richard Rubin, "Turnover Rates of Librarians," Journal of Library Administration 6:89-106 (Winter 1985-1986).

3. William Wong and David Zubatsky, "The Tenure Rate of University Library Directors: A 1983 Survey," College and Research Libraries 6:70-77 (Jan. 1985).

4. The ARL statistics compiled thus far do not include any breakdowns between professional and nonprofessional library employees. Total salary and wage expenditures for ACRL libraries listed in ACRL University Library Statistics, 1985-86 \& 1986 " 100 Libraries" Statistical Survey (Chicago: ACRL, 1987), p. 21 , range from $30 \%$ to $59 \%$ of the total operating expenditures, with a median of $47 \%$.

5. John L. Cotton and Jeffrey M. Tuttle, "Employee Turnover: A Meta-Analysis and Review with Implications for Research," Academy of Management Review 11:55-70 (1986).

6. Tenure at UNL is awarded on the basis of superior job performance; promotion depends on research, superior job performance, publication, and professional activities. 